\title{
Preserving the norm against chemical weapons: A civil society initiative for the 2018 4th review conference of the chemical weapons convention
}

\author{
Michael Crowley, Lijun Shang, Malcolm Dando \\ University of Bradford, Bradford, West Yorkshire, UK
}

Keywords:

Neuroscience

Chemical weapons

Chemical weapons convention

Biological and toxin weapons convention

Civil society initiative

\begin{abstract}
A B S T R A C T
Acceleration of the applications of cutting edge science is often most likely in situations involving conflict and warfare between different groups. That is the focus of this paper. It asks what we know of the past, present and possible future applications of advances in our understanding of the brain in the development of chemical weapons, and what might best be done to moderate the most dangerous aspects of that process at the present time, particularly by members of civil society. The paper therefore begins by examining this possibility of hostile manipulation of the brain in some detail. It then briefly reviews the current state of the chemical and biological arms control and disarmament regime as embodied in the Biological and Toxin Weapons Convention (BTWC) and the Chemical Weapons Convention (CWC) following the 2016 8th Five Year Review Conference of the BTWC and in the lead up to the 2018 4th Five Year Review Conference of the CWC. Finally, our civil society initiative to assist in achieving a successful outcome of the 2018 CWC Review Conference is described. This initiative involves the production of a multi-authored edited book, to be published in advance of the Review Conference by the UK Royal Society of Chemistry that explores many of the critical issues facing the CWC States Parties as they seek to agree effective measures to prevent the development and use of chemical weapons, as the life and chemical sciences advance.
\end{abstract}

\section{Introduction}

Catastrophic risks to the human species obviously can take many different forms, but the risks usually discussed involve the possible demise of the species. In this paper the risk considered is not the demise of the species, but its modification, as a result of the application of the ongoing advances in neuroscience, to forms that would not be seen as acceptable to many of us today. Such 'Brave New World' possibilities have certainly been considered in this century ${ }^{1}$ but accounts have frequently dealt predominantly with civil applications of neuroscience where there is the possibility of societal reflection on the implications of the applications and therefore mitigation of unacceptable aspects of the impacts on society. However, acceleration of the applications of cutting edge science is often most likely in situations involving conflict and warfare between different groups of the human species. So that is the focus of this paper. In short it asks what we know of the past, present and possible future applications of advances in our understanding of the brain in the development of chemical and biological weapons, and what might best be done to moderate the most dangerous aspects of that process at the present time, particularly by members of civil society.

\footnotetext{
* Corresponding author.

E-mail address: mrdando@bradford.ac.uk (M. Dando).

${ }^{1}$ Michael Bess (2016) Make Way for the Super Humans. Icon Books, London
} 
While this issue has not received the attention that for example misuse of synthetic biology, gain of function experiments and Artificial Intelligence have received, is important because it could be the initial stage in a longer-term process of degeneration. As Professor Matthew Meselson argued at the turn of the century²:

“...During the century ahead, as our ability to modify fundamental life processes continues its rapid advance, we will be able not only to devise additional ways to destroy life but will also become able to manipulate it - including the processes of cognition, development, reproduction and inheritance.... Therein could lie unprecedented opportunities for violence, coercion, repression, or subjugation..." (emphases added)

In particular, he argued further that:

“...Unlike the technologies of conventional or even nuclear weapons, biotechnology has the potential to place mass destructive capabilities in a multitude of hands and, in coming decades, to reach deeply into what we are and how we regard ourselves. It should be evident that any intensive exploitation of biotechnology for hostile purposes could take humanity down a particularly undesirable path. (emphasis added)

The paper therefore begins by examining this possibility of hostile manipulation of the brain in some detail. It then briefly reviews the current state of the chemical and biological arms control and disarmament regime as embodied in the Biological and Toxin Weapons Convention (BTWC) and the Chemical Weapons Convention (CWC) following the 2016 8th Five Year Review Conference of the BTWC and in the lead up to the 2018 4th Five Year Review Conference of the CWC. Finally, our civil society initiative to assist in achieving a successful outcome of the 2018 review is described. This initiative involves the production of a multi-authored edited book, to be published in advance of the review by the UK Royal Society of Chemistry that is intended to consider many of the critical scientific issues facing the States Parties at the Review Conference.

\section{Implications of a mechanistic neuroscience}

The early Stockholm International Peace Research Institute (SIPRI) study of The Problem of Chemical and Biological Warfare ${ }^{3}$ noted that at the beginning of the United States' incapacitating chemical agents research programme in the 1950s and 1960s many different ways of producing what one participant called selective malfunctions of the human machine ${ }^{4}$ seemed to be possible. The SIPRI study noted that the US Army Chemical Corps pointed out at least a dozen such possibilities and gave details on some of them and the agents that might be used (Fig. 1).

The strenuous efforts made to find effective chemical incapacitating agents during the Cold War period was neatly summarized in the 1997 version of the United States Textbook of Military Medicine: Medical Aspects of Chemical and Biological Warfare ${ }^{5}$ which stated bluntly that'[V]irtually every imaginable chemical technique for producing military incapacitation has been tried at some time.' Yet the difficulty of finding an agent that could be used effectively without the risk of killing some of those affected by the agent is well known. As the U K Royal Society pointed out in its 2012 study of Neuroscience, Conflict and Security, in addition to the potential side effects of the agent used to incapacitate ${ }^{6}$ :

"...when considered as a complete weapon system in an operational context, uncontrollable variables such as the size, health, age etc., of the target population, secondary injury (e.g. airway obstruction), and requirement for medical aftercare introduces further challenges to the development of a safe incapacitating chemical agent."

Nevertheless, efforts were made to discover such agents. One particular aspect of this search was noted, by the Scientific Advisory Board of the OPCW, in its report for the 3rd Review Conference of the CWC in 2013":

"...The types of chemicals and pharmaceuticals, known to have been considered as incapacitants from open literature sources, were discussed. Most are centrally acting compounds that target specific neuronal pathways in the brain. All of them emerged from [civil] drug programmes undertaken from the 1960s to the 1980s, as far as can be judged by the research that has been published."

We are seeing here is what has become known as the dual-use problem in the life sciences in that cutting edge civil scientific work is then used by the military for hostile purposes. Yet despite all the efforts these programmes were not based on a good enough understanding of the CNS for an effective chemical incapacitating agent to be produced. The problems were illustrated by the death of 125 of the 900 hostages when a mixture of fentanyl derivatives was used to break the 2002 Moscow theatre siege. ${ }^{8}$

\footnotetext{
${ }^{2}$ Meselson, M. (2000) Averting the hostile exploitation of biotechnology. The Chemical and Biological Weapons Conventions Bulletin, July, 16-19.

${ }^{3}$ Stockholm International Peace Research Institute, Volume II: CB Weapons Today. Almqvist \& Wiksell Stockholm, 1973, Chapter 4. Research and development: Implications for the future of CBW, pp 260-332.

${ }^{4}$ D. Lindsey (1960) Selective malfunctions of the human machine: New horizons in chemical warfare, Military Medicine, 1960, 125, 598.

${ }^{5}$ Ketchum, J.S. and Sidell, F.R. (1997) Incapacitating Agents, pp 287-306 in Textbook of Military Medicine: Medical Aspects of Chemical and Biological Warfare, eds F. R. Sidell, E. T Takafuji and D. R. Franz, Office of the Surgeon General, Department of the Army, United States, Washington D.C., 1997.

${ }^{6}$ Royal Society (2012) Neuroscience, conflict and security, Brain Waves Module 3, Royal Society, London,F ebruary.

${ }^{7}$ OPCW (2012) Report of the Scientific Advisory Board on Developments in Science and Technology for the Third Special Session of the Conference of the States Parties to Review the Operation of the Chemical Weapons Convention, RC-3/DG-1, OPCW, The Hague, 29 October.

${ }^{8}$ Riches, J. R. et al. (2012) Analysis of Clothing and Urine from Moscow Theatre Siege Casualties Reveals Carfentanyl and Remifentanyl Use. Journal of Analytical
} 


\begin{tabular}{|c|c|}
\hline System & Malfunction \\
\hline 1. Blood Pressure & Hypotension: fainting on sudden loss of blood pressure \\
\hline 2. Digestive System & Emesis: vomiting and retching \\
\hline \multirow[t]{2}{*}{ 5. Body temperature } & Increase: heatstroke and exhaustion \\
\hline & Decrease: sedation and unconsciousness \\
\hline 4. Labyrinthine reflexes & Lack of ability to balance: falling over \\
\hline \multirow[t]{2}{*}{ 5. Muscles } & Hypotonia: leading to paralysis \\
\hline & Tremors: leading to Parkinson's like effect \\
\hline 6. Vision & Blindness: for a temporary period \\
\hline 7. Higher functions & Various types of psychotrophic eftects \\
\hline
\end{tabular}

Fig. 1. Selective Malfunctions of the Human Machine.

It is that aspect of the situation which is changing fast at the present time as advances, for example in neuroimaging and optogenetics, enable rapid advances in our understanding of the operation of the CNS to be made. This point was made very clearly in a report for the United States Institutes of Health titled BRAIN 2025: A Scientific Vision. It argued that the analysis of the neuronal circuits underlying various behaviours was a particularly rich research area of opportunity and that'

“...Truly understanding a circuit requires identifying and characterizing the component cells, defining their specific connections with one another, observing their dynamic patterns of activity as the circuit functions in vivo during behavior, and perturbing these patterns to test their significance. It also requires an understanding of the algorithms that govern information processing within a circuit and between interacting circuits in the brain as a whole...."

Of course, given the prevalence of mental illnesses around the world and the distress that is caused we would all like to see progress in brain research, but it is necessary also to be aware of the potential for misuse.

These dangers have been recognised by a growing number of States Parties to the Chemical Weapons Convention. For example, in 2014 Australia produced a paper that stated $^{10}$ :

"The weaponisation of CNS acting chemicals for law enforcement purposes is of concern to Australia due to the health and safety risks and the possibility of their deliberate misuse, both of which have the potential to undermine the global norm against the use of toxic chemicals for purposes prohibited by the Convention."

This was followed up in 2015 by a paper by Australia and 21 other CWC States Parties entitled Aerosolisation of Central Nervous System Acting Chemicals for Law Enforcement Purposes ${ }^{11}$ that identified "preventing the re-emergence of chemical weapons, including new types of potential chemical agents" as a particular concern. Under the Chemical Weapons Convention the use of certain toxic chemicals for peaceful purposes, notably "[L]aw enforcement including domestic riot control purposes ${ }^{12}$; is allowed, provided the "types and quantities" of such chemicals are consistent with such purposes. ${ }^{13}$ Whilst riot control agents (e.g. tear gas and pepper spray) are clearly allowed for such law enforcement purposes, the permissibility of employing a range of other toxic chemicals, notably incapacitating chemical agents, is contested among the CWC States Parties. If this issue is not clarified by a joint agreement amongst the CWC States, so that only riot control agents as standardly understood can be used for law enforcement purposes by the police and military, there is considerable risk that weapons employing novel toxic chemical agents will be developed as our understanding of the CNS increases, and we will enter into a very slippery slope as the century unfolds.

Evidence of military and law enforcement interest and concern about the development of such agents is clear from the publication of a series of influential reports in the United States since the turn of the century (Fig. 2), and in the kinds of concerns that are expressed in these reports (Fig. 3).

So there is a clear danger that some may feel that it is possible that 'incapacitating' weapons employing novel toxic chemicals can be developed on the back of the ongoing advances in neuroscience. ${ }^{14}$ The question at issue is whether the situation has changed since the period of the East/West Cold War and if it is now possible that sufficient advances have been made in regard to the neuronal circuits underlying some aspects of our behavior for selective malfunctions to be possible in a way that they were not possible previously?

During the Cold War perioid considerable efforts were made to find chemical incapacitating agents from a wide range of potential

(footnote continued)

Toxicology, 36, 647-656.

${ }^{9}$ Brain Research through Advancing Innovative Neurotechnologies (BRAIN) Working Group (2014) Report to the Advisory Committee to the Director, NIH: Brain 2025: A Scientific Vision, National Institutes of Health Washington, D. C ., 5 June.

${ }^{10}$ Australia (2014) Weaponisation of Central Nervous System Acting Chemicals for Law Enforcement Purposes, C-19/ NAT.1, OPCW, The Hague, 19 November.

${ }^{11}$ Australia et al. (2015) Aerosolisation of Central Nervous System-Acting Chemicals for Law Enforcement Purposes, C-20/ NAT.2, OPCW, The Hague, 24 November.

${ }^{12}$ Chemical Weapons Convention, OPCW,1997, Article art. II.9(d).

${ }^{13}$ Chemical Weapons Convention, OPCW,1997, Article. II.1. a.

${ }^{14}$ Dando, M. R. (2015) Neuroscience and the Future of Chemical-Biological Weapons. Palgrave/Macmillan. 
1. The Advantages and Limitations of Catmatives for Use as a Non-Lethal

Techmique. Applied Research Laboratory of the College of Medicine,

Pennsylvania State University (2000).

2. Lmerging Cognitive Neuroscience and Related Technologies. National

Research Council, US National Academy of Sciences (2008).

3. Upportumities in Neuroscience for Future Army Applications. National

Research Council, US Natıonal Academy of Sclences (2009).

4. Human Performance Modification: Review of Worldwide Research with a

View to the Future. National Research Council, Us National Academy of

Sciences (2012).

Fig. 2. Some studies in the United States since 2000 involving incapacitating chemical agents.

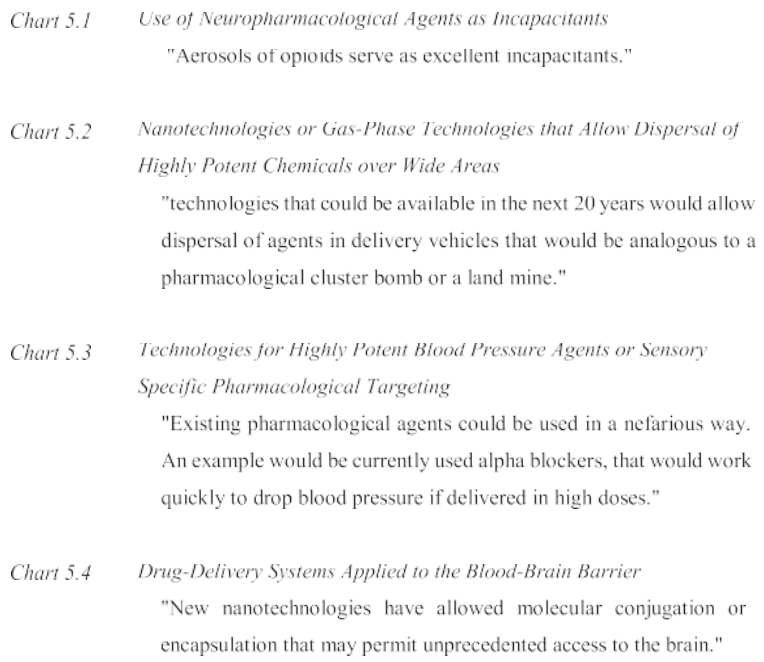

Fig. 3. Some potential development areas of concern identified in Emerging Cognitive Neuroscience and Related Technologies.

chemical agent types., However, as the 1997 United States' Textbook on Military Medicine ${ }^{15}$ pointed out that '[F]rom this large number of possibilities chemicals in a single group - the "anticholinergics" - are regarded as most likely to be used as military incapacitating agents." This group included BZ (3-qyinuclidinyl benzilate) which was weaponised but never used by the United States. That opinion could not take into account the events in Moscow in 2002 and the attempt to use fentanyl derivatives as incapacitating agents. The current position was put by the Royal Society 2012 report in which it commented that ${ }^{16}$ :

"...with increasing emphasis on rapid action and short duration of effects, contemporary interest has tended to focus on sedativehypnotic agents that reduce alertness and as the dose increases, produce sedation, sleep, anaesthesia and death."

So, analysis of the present possibilities is complex because it is necessary to consider not only potential novel agents revealed by modern research work in the civil sector but also what work has been done on older agents that might make them more attractive than they were in the past and what work is being done on currently considered agents like fentanyl derivatives which could also make them more attractive as incapacitating agents.

It is well known that in the early years of the Cold War research was carried out on psychedelics like LSD that have a similar structure to the neurotransmitter serotonin (5-hyndroxytrytamine, 5-HT) but that work was abandoned partly on the grounds that the effects of the agent on people was just too unpredictable. ${ }^{17}$ Moreover concerns about the civil misuse of such drugs led to severe restrictions on LSD's use even in research. However, in recent years there has been a renewed interest in civil research on the impact of psychedelics on the brain and considerable advances in our understanding of how they disrupt brain circuits. ${ }^{18}$ This work could well lead to useful results both in facilitating our understanding of complex brain functions and in helping people suffering from mental illnesses, but it needs to be borne in mind that there could be dual-use potential in the results from this resurgence. Similarly, marijuana was investigated as an incapacitating agent during the early Cold War period but it was discarded as a potential agent as it did not have sufficient potency. However, since that time the cannabinoid receptors that it affected in the brain, and the natural

\footnotetext{
${ }^{15}$ See reference 5 .

${ }^{16}$ See reference 6

${ }^{17}$ Ministry of Defence, Historical Survey of the Porton Down Service Volunteer Programme 1939-1989, Part IV, Human studies with incapacitating agents, 109-141, Ministry of Defence, London, June, 2006.

${ }^{18}$ Carhart-Harris, R. L. et al. (2016) Neural correlates of the LSD experience revealed by multimodal neuroimaging, PNAS, 113, $4853-4858$.
} 
neurotransmitters for these receptors, have been discovered. Moreover, there has been a steady evolution of the development and use of more powerful forms of illicit synthetic agents that affect these receptors. This civil research is revealing interesting insights into the operations of the neuronal circuits in the brain and helping us to understand the dangers of using such chemicals for recreational purposes, ${ }^{19}$ but again it would be sensible to keep the potential for hostile misuse in mind.

The first report shown in Fig. 2 The Advantages and Limitations of Calmatives for Use as a Non-Lethal Technique was published in 2000 and was carried out by the Applied Research Laboratory of the College of Medicine at Pennsylvania State University. It clearly built on the advances made in our understanding of the receptors in the brain during the previous decade, and concluded that ${ }^{20}$ :

“...Researchers identified several drug classes (e.g. benzodiazepines, alpha2-adrenoreceptor agonists) and individual drugs (diazepam, dexmedotomidine) found appropriate for immediate consideration as a non-lethal technique..."

The authors suggested that by using combinations of agents the dangerous side effects of these currently topical agents might be reduced. This was precisely the approach taken by Czech scientists in the early years of this century in their work on what they called "pharmacological non-lethal weapons". They stated that ${ }^{21}$ :

"Fully reversible analgesic sedation was also tested in man. We tested the triple combination of dexmedetomidine $1 \mu \mathrm{mg} \mathrm{kg}^{-1}$, midazolam $0.08 \mathrm{mg} \mathrm{kg}^{-1}$ along with fentanyl $1 \mathrm{\mu g} \mathrm{kg}^{-1} \ldots$. The onset of effect following administration...was very rapid, with appreciable psychomotor sedation seen within 2-3 min. Sleep set in within $57 \mathrm{~min} . . . "$ (original emphases)

Fortunately, the Czech authorities have subsequently made it clear that researchers could not be involved in the development of such so-called non-lethal weapons under the law in the Czech Republic, but the dangers of proceeding down that path are made clear by this recent example.

Looking to the future inevitably raises the question of what will be the outcome of our increasing understanding of the role of the numerous neuropeptides that are being found to be active in the brain. An example of how fast advances can take place concerns the neuropeptide called orexin (also confusingly called hypocretin). This has a clear role in the sleep disease narcolepsy because if it is not present in the brain narcolepsy occurs. Yet nothing was known about this neuropeptide -even its existence - until the late 1990s. A recent scientific review stated that ${ }^{22}$ :

“...Compared to other neurotransmitters and neuropeptides, the orexin/hypocretin system represents the new kid on the block. First identified only in 1998, the past fifteen years has seen a steady growth in understanding of the roles that orexin receptors and their cognate peptide ligands play in the CNS and beyond..."

The progress has been such that drugs (antagonists) that block the orexin receptors in the brain have been developed already as a means of dealing with the widespread problem of insomnia. ${ }^{23}$

Given that pace of change, and there are many other examples that could be cited, it is hard to disagree with the conclusion of a 2012 official UK paper for a meeting of the BTWC in Geneva which stated that ${ }^{24}$ :

"...Many of the benefits and risks in the neurosciences lie in the future. However, in the development phase it is timely to consider issues related to governance of this dual-use technology area, balancing the obligation to take measures to prohibit and prevent misuse with the need to ensure that the beneficial development of science is not hampered..."

There would appear to be substantial risks of misuse if this kind of proactive approach is not taken. It needs to be remembered that a recent account of the early Cold War United States programme quoted one scientific director ${ }^{25}$ as stating that the symptoms of value to the programme included "fits or seizures, dizziness, fear, panic, hysteria, hallucinations, migraine, delirium, extreme depression, notions of hopelessness, lack of initiative...even suicidal mania." Such selective manipulations of the human machine may not have been possible then, but they may be implemented in the future if we are not careful.

Therefore, the argument put forward here is that the development of these novel agents in the current unstable international system could open up avenues to much more dangerous modifications of the operations of our central nervous systems as the revolution in the neurosciences proceeds during this century and that one outcome of a successful CWC Review Conference in 2018 would be a clear agreement that such CNS-acting weapons using such agents should not be developed.

\section{The disarmament regime today}

Following the First World War the 1925 Geneva Protocol banned the use of chemical and biological weapons in warfare, but it

\footnotetext{
${ }^{19}$ Skosnik, J. A. et al. (2016) It's All in the Rhythm: The Role of Cannabinoids in Neural Oscillations and Psychosis. Biological Psychiatry, 79, $568-577$.

${ }^{20}$ Lakoski,J.M.etal.(2000) The Advantages and Limitations ofCalmativesfor Useasa Non-Lethal Technique, College of Medicine, Applied Research Laboratory, The Pennsylvania State University, October 3.

${ }^{21}$ European Working Group on Non-Lethal Weapons (2005) Proceedings of the 3rd European Symposium on Non-Lethal Weapons, Pfinztal, Frankfurt ICT, V23, L. Hess, J. Schreiberova and J. Fusek, Pharmaceutical Non-Lethal Weapons, p 7-9.

22 Langmead, C. L. (2014) From orphans to orexins: an arousing fifteen years. British Journal of Pharmacology, 171, $281-282$.

${ }^{23}$ Winrow, C.J. and Renger, J. J. (2014) Discovery and development of orexin receptor antagonists as therapeutics for insomnia. British Journal of Pharmacology, $171,283-293$.

${ }^{24} \mathrm{UK}$, The convergence of chemistry and biology: implications of developments in neurosciences, BWC/MSP/MX/WP.1 United Nations, Geneva, 12 July 2012.

${ }^{25}$ Khatchadourian, R. (2012) Operation Delirium. The New Yorker, December 17, http:/ / www.newyorker.com/ magazine/2012/12/17/ operation-delirium, last Accessed 16/03/2016.
} 
was not until the 1970s that the BTWC was agreed and not until the 1990s that the CWC was negotiated. During the intervening decades much more dangerous and effective chemical and biological weapons were developed in numerous State-level offensive programmes and some actually employed with devastating effects, notably Iraq's use of mustard gas and nerve agents in its war with Iran and against its own citizens at Halabja and elsewhere. And we have seen chemical and biological weapons use continue into this century - in the anthrax letter attacks in the United States and the employment of nerve agents, mustard gas and weaponized chlorine in the Syrian civil war.

In terms of biological weapons, the BTWC adds a series of further restrictions to the Geneva Protocol's ban on use in its first Article which states that ${ }^{26}$ :

"Each State Party to this Convention undertakes never in any circumstance to develop, produce, stockpile or otherwise acquire or retain:

1. Microbial or other biological agents, or toxins whatever their origin or method of production, of types and in quantities that have no justification for prophylactic, protective or other peaceful purposes..."

This Article encapsulates what has become known as the 'General Purpose Criterion' in that it covers all possible misuse of the life sciences now and in the future. Unfortunately this sweeping prohibition is not backed up because the Convention does not have a major international organization to take care of it between its Review Conferences, and attempts to develop a verification system to ensure that States Parties lived up to their obligations failed in 2001. ${ }^{27}$ Following that failure States Parties agreed a series of Intersessional Processes - annual meetings between the Five Year Review Conferences - in the hope of making progress on less politically difficult issues.

While scientific and technological advances was progressively more prominent in the agenda of these annual meetings, by 2016 it was clear that many States Parties expected that a much more effective and efficient system would have to be put in place at the 8th Review Conference. The Review Conference unfortunately was not a success and really all that could be agreed was to meet again at the end of 2017 in the hope of doing better. At the time of writing this paper in mid 2017 it is not at all clear if any substantial progress can be made at the end of the year. The future of the BTWC is therefore uncertain and influential voices suggest that the best way forward may be to leave the Convention as a 'norm setting' statement and to try to implement what needs to be done by other modular means. ${ }^{28}$ In such circumstances, ensuring comprehensive and correct implementation of the Chemical Weapons Convention by all State Parties becomes even more important to the strength of the whole regime.

The CWC certainly is widely seen as a much stronger agreement than the BTWC because it has a major international organization - the Organisation for the Prohibition of Chemical Weapons (OPCW) - located in The Hague and has successfully and verifiably overseen the destruction of the huge and dangerous stocks of lethal chemical weapons built up by States during the last century. Yet now the CWC has to make an adjustment away from disarmament to the kind of complex task that has faced the BTWC - of preventing the re-emergence of chemical weapons - in a period of rapid scientific and technological change and in a complex international system involving much asymmetric conflict. In addition to the problem of the potential development of novel 'nonlethal' chemical agents, the difficulties involved are well illustrated by the use of lethal chemical weapons in Syria including sarin, sulpur mustard and weaponized toxic industrial chemicals; and elsewhere by the assassination of Kim Jong-nam in Kuala Lumpur airport with the deadly nerve agent VX.

\section{Civil society initiative}

As the 4th Review Conference of the CWC approaches in late 2018 there will be many State-level papers and reports produced in order to inform the deliberations, but given the nature, for example of the wide ranging relevant scientific and technological advances, taking place it seems that civil society also could have much to contribute. Therefore, we decided to attempt to put together in one place a diverse set of contributions covering a good deal of the more scientific issues likely to be under consideration at the Review Conference and of the contributions that civil society has and could have in the future in the consideration of these issues. The result was a book titled Preventing Chemical Weapons: Arms Control and Disarmament as the Sciences Converge. ${ }^{29}$ The sections and chapters of the book are set out in Fig. 4.

The book consists of 21 chapters divided into six major sections. The first chapter, by the editors, sets out the Holistic Arms Control (HAC) ${ }^{30}$ analytical framework which informs the book, and which consists of the following three stage process:

- Stage one: examination of the nature of the weapons and technology to be controlled; current and potential future scenarios of application, together with attendant national and human security concerns; and potential implications of science and technology developments.

\footnotetext{
${ }^{26}$ The full text of the BTWC can be found on the BTWC section of the United Nations Website in Geneva.

${ }^{27}$ Dando, M.R. (2002) Preventing Biological Warfare: The Failure of American Leadership. Palgrave/Macmillan, Basingstoke.

${ }^{28}$ Lennane, R. (2016) Divide and Delegate: The Future of the BWC. Paper No. 1, BWC Review Conference Series, International Law and Policy Institute, Oslo, Norway. Available at $<$ ilpi.org $>$

${ }^{29}$ M. Crowley, L. Shang and M. R. Dando (Eds.) Preventing Chemical Weapons: Arms Control and Disarmament as the Sciences Converge. Royal Society of Chemistry London (in press)

${ }^{30}$ Crowley, M. (2016) Chemical Control: Regulation of Incapacitating Chemical Agent Weapons, Riot Control Agents and their Means of Delivery. Palgrave/Macmillan, Basingstoke.
} 


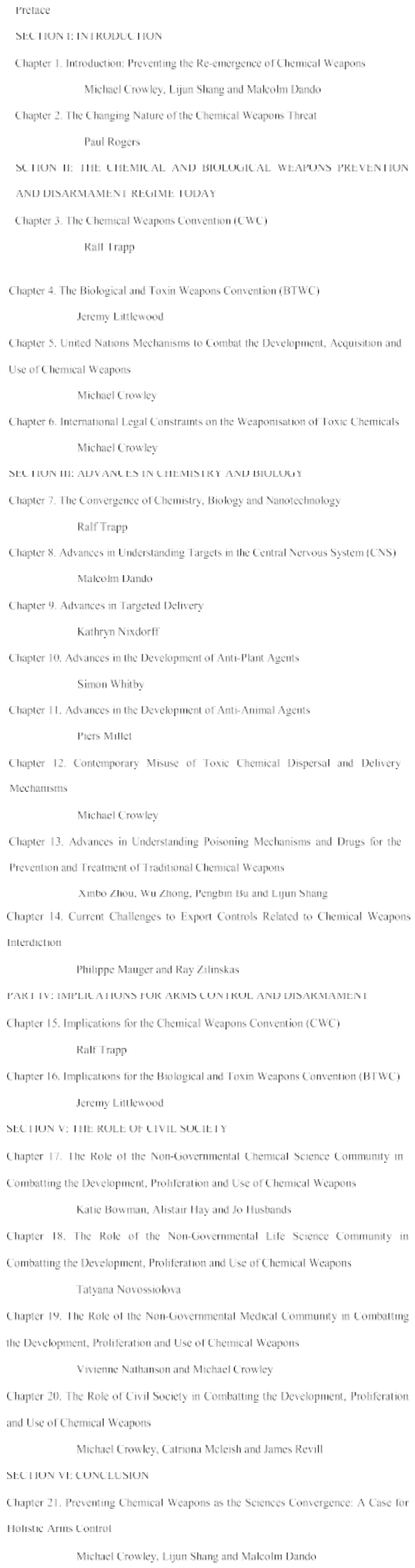

Fig. 4. Preventing Chemical Weapons: Arms Control and Disarmament as the Sciences Converge.

- Stage two: exploration of the full range of potentially applicable control mechanisms; analysing strengths, weaknesses and limitations.

- Stage three: development of a comprehensive strategy to improve existing mechanisms (and/or introduce additional measures) for 
the effective regulation or prohibition of the weapon or weapons-related technology of concern.

In Chapter 2 Paul Rogers provides an overview of the very different international security system that has evolved since the end of the East-West Cold War and how asymmetric warfare within that novel system may well encourage the use of forms of chemical warfare by parties involved. Section II then gives a summary of the state of the chemical weapons prevention and disarmament regime today with contributions by Ralf Trapp on the Chemical Weapons Convention (Chapter 3), Jeremy Littlewood on the Biological and Toxin Weapons Convention (Chapter 4) and Michael Crowley on other United Nations mechanisms designed to combat the development, acquisition and use of chemical weapons (Chapter 5) and wider international legal constraints on the weaponisation of toxic chemicals (Chapter 6).

Section III forms the largest part of the book with a series of chapters on the advances in relevant science and technology. Chapter 7 by Ralf Trapp considers the continuing convergence of the sciences of chemistry, biology and nanotechnology and the implications of these advances. In Chapter 8 Malcolm Dando describes some of the advances in our understanding of the operation of the Central Nervous System and how this may open up the possibility of the design of novel agents. Kathryn Nixdorff, in Chapter 9 then discusses the advances being made in our capabilities in targeting agents to designated sites in living systems. Advances in anti-animal and anti-plant agents are dealt with by Simon Whitby in Chapter 10, and Piers Millet in Chapter 11. Michael Crowley in Chapter 12 examines contemporary misuse of existing chemical delivery and dispersal mechanisms and explores potential implications of further technological advance of such mechanisms. The section ends with a review of advances in our capabilities for prevention and treatment of traditional chemical agents by Xinbo Zhou, Wu Zhong, Pengbin Bu and Lijun Shang in Chapter 13, and of the challenges to the current export control system produced by the changing nature of the marketing of relevant goods through the internet by Philippe Mauger and Ray Zilinskas in Chapter 14.

The implications of these advances for the disarmament regime are then the subject of the chapters in Section IV. Chapter 15 by Ralf Trapp deals with the implications for the CWC, and Chapter 16 by Jeremy Littlewood with the implications for the BTWC.

Given the importance of a broad range of viewpoints being available to the 4th Review Conference of the CWC in 2018, Section V is devoted to an investigation of the ways in which civil society has attempted to assist in combatting the development and use of chemical weapons and of how it might continue such efforts in the future. In Chapter 17 Katie Bowman, Alistair Hay and Jo Husbands detail the Non-Governmental chemical community's efforts, Tatyana Novossiolova deals with the Non-Governmental life science community's efforts in Chapter 18 and Vivienne Nathanson and Michael Crowley cover the work of the Non-Governmental medical community in Chapter 19. In Chapter 20 Michael Crowley, Catriona Mcleish and James Revill then consider the work of informed and activist civil society more broadly.

The final Section VI of the book contains the concluding Chapter 21 by the editors. Here we employ the Holistic Arms Control framework as a means of analysing the contributions of the preceding chapters and synthesising them into a proposed integrated approach which would prioritise the most appropriate and effective mechanisms to address the threats arising from the rapid advances in the chemical, life and related sciences and technologies; and more generally the dangers of the development, proliferation and use of existing or new forms of weapons employing toxic chemicals. Given its central importance to these considerations, the editors give particular attention to the CWC and the accompanying implementation and verification regime, and propose a range of recommendations for both States and civil society to strengthen OPCW action in these areas, at the 4th Review Conference and beyond.

\section{Conclusions}

The Holistic Arms Control approach taken in this civil society initiative is based on the view that to achieve success it is necessary to support the central arms control and disarmament agreements through the use of all other potentially relevant instruments and to involve a wide range of civil society groups in the effort. In particular, in this initiative we attempted to engage with the work of chemists, life scientists and medical doctors in support of the chemical and biological disarmament regime as is evident from the chapters of the book set out in Fig. 4.

This involvement of scientists in the broader societal issues impacted by their work is, of course, an example of a much wider movement in science and technology. As the InterAcademy Partnership stated in their recent publication Doing Global Science: A Guide to Responsible Conduct in the Global Research Enterprise ${ }^{31}$ :

“....History has demonstrated that the unfettered pursuit of new knowledge has many benefits.... Nevertheless, research in some areas poses risks, and these risks need to be anticipated and minimized to the extent possible in the planning, performance, and dissemination of research.

If this approach is taken to the risks posed by scientific advances we would suggest that scientists would become to be seen more as part of the solution rather than the cause of the problem.

More generally in regard to civil society's support for upholding the prohibition on the development and use of chemical and biological weapons, as Crowley, McLeish and Revill argue in the penultimate chapter of Preventing Chemical Weapons there are many ways in which civil society can act. These activities include:

\footnotetext{
${ }^{31}$ InterAcademy Partnership (2016) Doing Global Science: A Guide to Responsible Conduct in the Global Research Enterprise. Princeton University Press Princeton
} 
- responding to reported chemical weapons events through providing information pertinent to or supportive of investigations; challenging unverified claims; documenting the human consequences of chemical weapons attack; providing medical assistance to victims of such attacks; identifying agents used; and trying to hold manufacturers and governments to account.

- undertaking technology-tracking of technologies of relevance to the CWC.

- providing expert scientific advice, for example in development and testing verification methodologies for governments to consider.

- promoting and generating transparency into the activities of governmental and non-governmental research activities potentially relevant to the development of chemical weapons.

- supporting whistle blowers seeking to expose activities potentially relating to the development, proliferation and use of chemical weapons.

- fostering engagement between governmental actors through track-two processes.

- Seeking to reframe the discourse around the development, possession and use of chemical weapons, highlighting human security and human rights considerations.

However, it is also important to recognise that although the network of civil society actors who support the prohibition has grown in recent years there are limits to what civil society can usefully do. These limitations result in part from chemical weapons issues being traditionally framed in terms of a State security discourse with only narrow scope for the involvement of non-state actors.

Yet dealing effectively with the challenge of chemical warfare in the 21st Century is unlikely to be achieved by States alone. Rather it will require governments working with a much wider range of stakeholders, including the chemical industry, independent scientific and medical researchers, academics, NGOs, and wider civil society. That has been recognised by some governments, however the extent to which such governments are willing to open chemical disarmament diplomacy to a wider civil society audience is unclear; as is the extent to which other states less receptive to civil society engagement would be willing to change longstanding institutional practices.

Similar considerations, of course, apply to other examples of the governance of emerging technologies and the catastrophic risks that may result from their mismanagement. 